\title{
Numerical \& Analytical Analysis of the Low Cycle Fatigue Behavior of Notched \& Un-notched 316 L (N) Austenitic Stainless Steel Samples at Ambient and Elevated Temperatures
}

\author{
Ikram Abarkan 1,*, Abdellatif Khamlichi' ${ }^{1}$, Rabee Shamass² \\ ${ }^{1}$ ESD Laboratory, Abdelmalek Essaadi University, 93002 Tetouan, Morocco; *aberkan.ikram-etu@uae.ac.ma \\ ${ }^{2}$ Division of Civil \& Building Services Engineering, School of Build Environment \& Architecture, London South Bank University, \\ London 103, United Kingdom.
}

\section{A B S T R A C T}

The present research mainly focuses on the; i) assessment of maximum local strains for circumferentially notched samples, ii) evaluation of some of the commonly known low cycle fatigue life methodologies for notched and un-notched specimens made of 316L (N) austenitic stainless steel and subjected to strain-controlled mode at ambient and higher temperatures, iii) proposal of a new equation and adjustable parameters to rectify the inconsistency of some of the widely used LCF analytical methods for notched and un-notched parts, respectively.

\section{INTR ODUCTION}

In the power plant industry, Low Cycle Fatigue (LCF) is considered a major failure mode for structural components operating at very high temperatures. For these components to function for a long time, materials with good creep, oxidation, and LCF properties are needed. $316 \mathrm{~L}(\mathrm{~N})$ Stainless Steel (SS) base metal is the typical material for sodium-cooled fast reactors due to its outstanding mechanical, LCF, and anti-corrosion properties. Besides, accurate LCF life prediction methods are usually required to estimate the lifetime for both notched and un-notched parts. For the former, exact values of the local strains are essential to determine precisely the fatigue life.

\section{EXPERIMENT\&SIMULATION}

\section{- Experiment:}

- The experiments on notched and smooth specimens were done separately.

- Six smooth and eighteen notched specimens were tested under fully reversed LCF loadings, i.e. $R \varepsilon=-1$.

- The nominal strain amplitude was ranging between $\pm 0.4 \%$ and $\pm 1 \%$, and from $\pm 0.3 \%$ to $\pm 1 \%$, for notched and un-notched samples, respectively.

- For the smooth samples, all the LCF tests were carried out at an ambient temperature, while for the notched ones, nine were conducted at ambient temperature and the other nine at $550{ }^{\circ} \mathrm{C}$.

- The experiments were performed at a constant strain rate of $3.10^{-3}$ $s^{-1}$, and in the air environment.

- The smooth and notched specimens' shape and dimensions are illustrated in Fig.1.

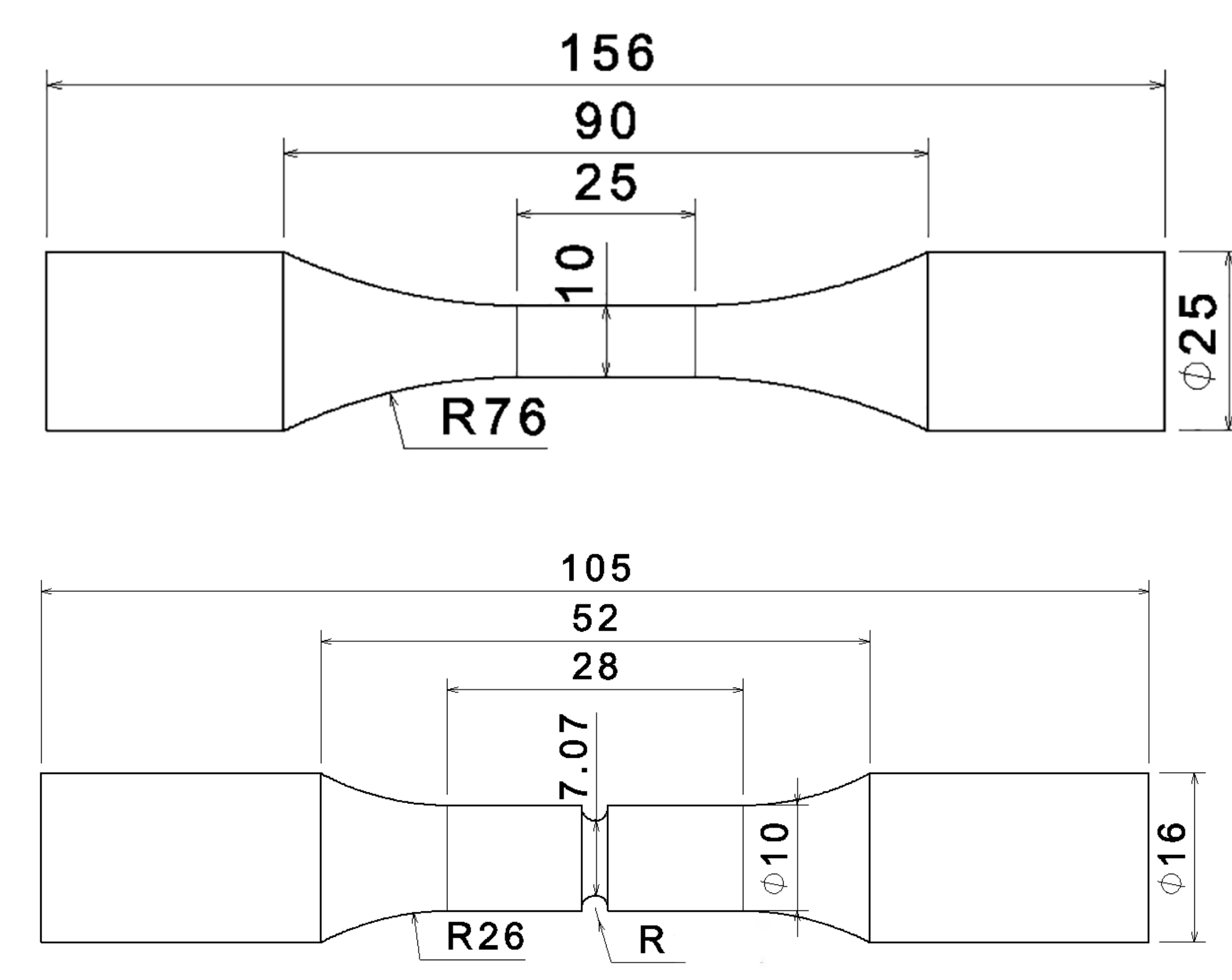

(a)

Fig. 1. Shape and dimensions (in mm), for (a) un-notched samples and (b) notched samples $(R)=1.25 / 2.5 / 5 \mathrm{~mm}$.

\section{Simulation:}

- The same abovementioned characteristics have been used to perform the LCF simulation on the notched specimens using the ABAQUS software.

- 2D axisymmetric model has been used.

- The material model implemented in the software is the cyclic Ramberg-Osgood.

- Mesh refinement technique has been applied to the notch-root of the specimens under study.

- Axisymmetric boundary conditions and prescribed displacement have been applied to the 2D model.

\section{MAXIMUM LOCAL STRAIN RESULTS}

- The maximum local strain is calculated, for each applied strain amplitude and notch root radius, using four well-known approximation methods.

The analytically obtained maximum local strains are compared with those found numerically from Finite Element Analysis (FEA), as depicted in Fig.2.
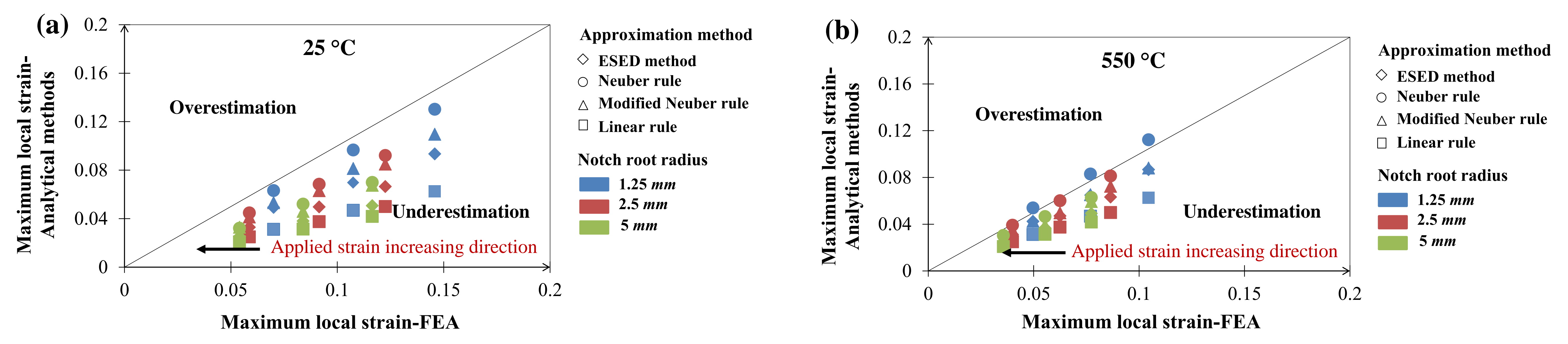

Fig. 2. Comparison between the analytically and the numerically obtained maximum local strains for different nominal strain amplitudes and notch root radii, (a) at $25^{\circ} \mathrm{C}$, and (b) at $550^{\circ} \mathrm{C}$.

The maximum local strains obtained analytically are not consistent with those found from FEA, mainly at $25^{\circ} \mathrm{C}$.

\section{FATIGUE LIFE RESULTES FOR NOTCHED SAMPLES}

- The fatigue life for each notched specimen is initially calculated using the commonly known strain-life equation, based on the maximum local strains obtained analytically.
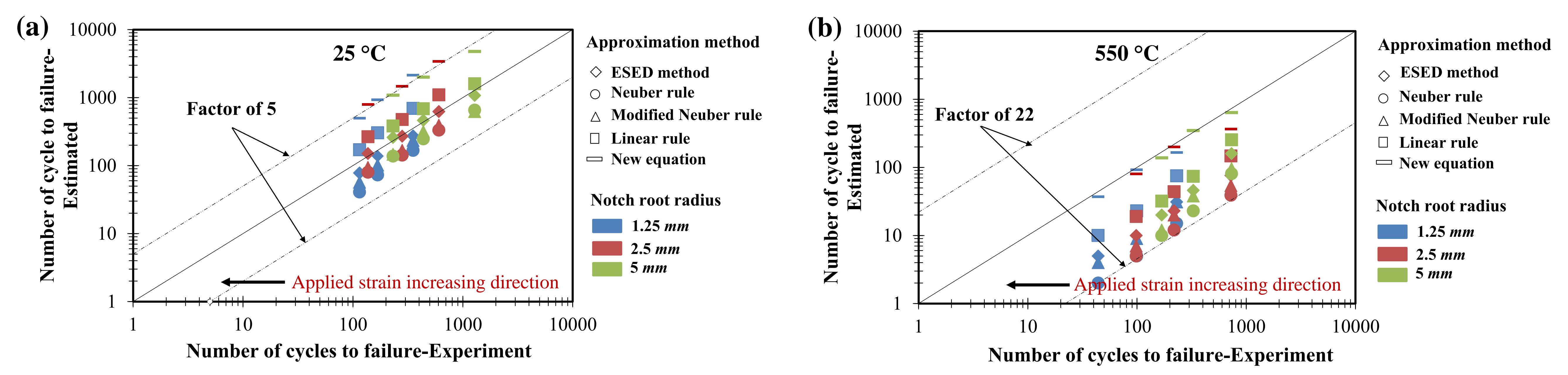

Fig. 3. Comparison between the predicted and the experimental fatigue lifetimes for different nominal strain amplitudes and notch root radii, (a) at $25^{\circ} \mathrm{C}$, and (b) at $550^{\circ} \mathrm{C}$.

$\Rightarrow$ The analytical results do not match well with the experimental data, particularly at $550{ }^{\circ} \mathrm{C}$. Hence, a new equation is proposed to predict the LCF life of notched parts.

$\Rightarrow$ As seen from Fig.3, the new equation allows a better fatigue life estimation compared with all other analytical methods at $550^{\circ} \mathrm{C}$. However, it provides non-conservative results at ambient temperature.

\section{FATIGUE LIFE RESULTES FOR UN-NOTCHED SAMPLES}

- The LCF life for each smooth specimen is initially estimated using the following Langer equation: $\Delta \varepsilon_{a}=C N_{f}^{\alpha}+S_{e} / E$ Where; $\Delta \varepsilon_{a}$ is the applied strain range, $S_{e}$ is the endurance limit, $E$ is Young's modulus, $C$ and $\alpha$ are material constants.

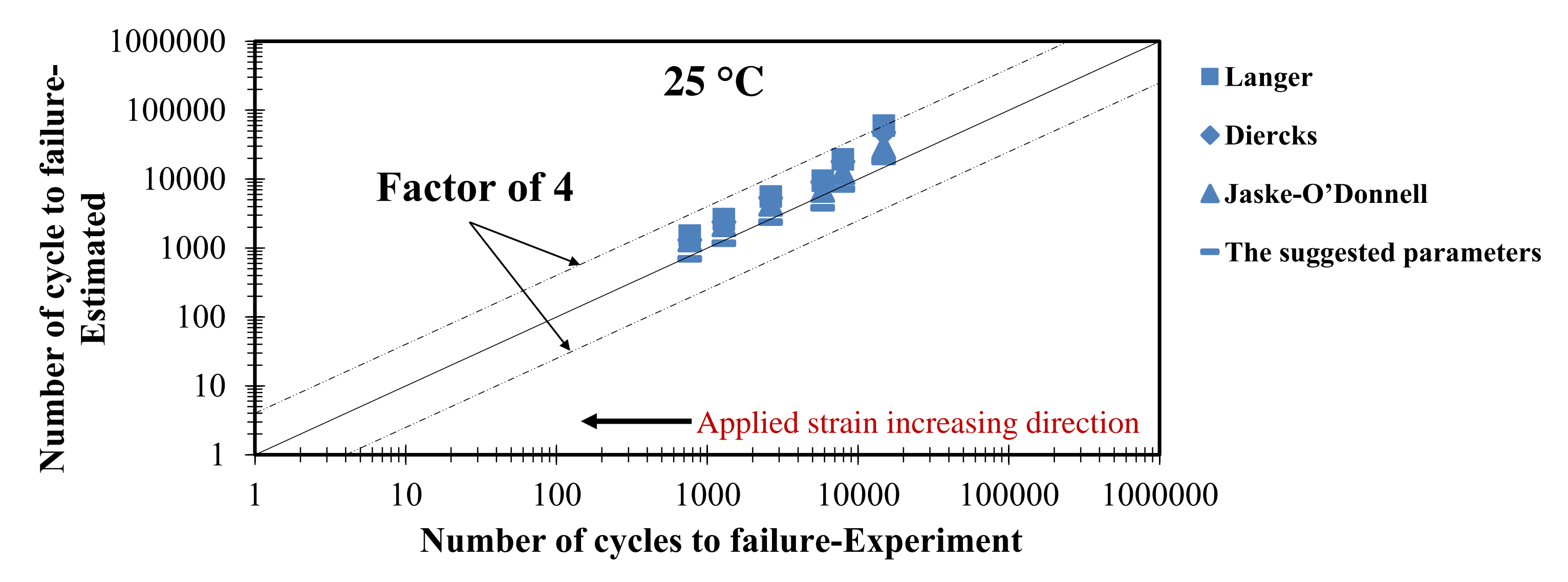

Fig. 4. Comparison between the predicted and the experimental LCF lifetimes.

$\Longrightarrow$ As illustrated in Fig.4, the estimated fatigue lifetimes using the Langer equation and its modified versions are not conservative. Therefore, new parameters are proposed to accurately predict the LCF life of smooth parts.

$\Longrightarrow$ The obtained fatigue lifetimes using the current study suggested parameters are in good agreement with the experimental data.

\section{CONCLUSIONS}

- The widely used fatigue life prediction methods for un-notched specimens have led to unsafe prediction results, and those of notched samples were found to give a strongly conservative estimation for applied strain amplitudes ranging from $\pm 0.3 \%$ to $\pm 1.0 \%$, and \pm 0.4 to $\pm 0.8 \%$, at 25 and $550{ }^{\circ} \mathrm{C}$, respectively.

- Accurate fatigue life results were obtained by using the currently suggested parameters and equation for un-notched and notched $316 \mathrm{LN}$ ) SS samples, at 25 and $550{ }^{\circ} \mathrm{C}$, respectively.

\section{RE F E R E N C ES}

[1] Abarkan, I., Khamlichi, A., and Shamass, R., 2020.A study on low cycle fatigue life assessment of notched specimens made of 316LN austenitic stainless steel, ASME Journal of Pressure Vessel Technology, submitted for publication.

[2] Abarkan, I., Shamass, R., Achegaf, Z. and Khamlichi, A., 2020. Numerical and analytical studies of low cycle fatigue behavior of $316 \mathrm{LN}$ austenitic stainless steel. ASME Journal of Pressure Vessel Technology. 